Jay M. Pescatore*, DO, Juan Sarmiento, MD, Ruben A. Hernandez-Acosta, MD, Britt Skaathun, PhD, MPH, Nancy Quesada-Rodriguez, MD and Katayoun Rezai, MD

\title{
Glycemic control is associated with lower odds of mortality and successful extubation in severe COVID-19
}

https://doi.org/10.1515/jom-2021-0182

Received July 12, 2021; accepted September 21, 2021;

published online December 16, 2021

\begin{abstract}
Context: Corticosteroids, specifically dexamethasone, have become the mainstay of treatment for moderate to severe COVID-19. Although the RECOVERY trial did not report adverse effects of corticosteroids, the METCOVID (Methylprednisolone as Adjunctive Therapy for Patients Hospitalized with COVID-19) study reported a higher blood glucose level in patients receiving methylprednisolone.

Objectives: This study aims to analyze the association between corticosteroids and COVID-19-related outcomes in patients admitted to the medical ICU (MICU) for COVID-19 pneumonia.

Methods: This is an observational study of 141 patients admitted to the MICU between March 18 and June 7, 2020. Data on demographics, laboratory and imaging studies, and clinical course were obtained, including data on corticosteroid use. Bivariate analyses and logistic regression were performed between patient characteristics and mortality and successful extubation.
\end{abstract}

\footnotetext{
*Corresponding author: Jay M. Pescatore, DO, Department of Medicine, John H. Stroger Hospital of Cook County, 1950 W Polk Street, Chicago IL 60612, USA, E-mail: jay.pescatore@cookcountyhhs.org. https://orcid.org/0000-0003-1821-6566

Juan Sarmiento, MD and Ruben A. Hernandez-Acosta, MD, Department of Medicine, John H. Stroger Hospital of Cook County, Chicago, IL, USA

Britt Skaathun, PhD, MPH, Department of Medicine, University of California, San Diego, La Jolla, CA, USA

Nancy Quesada-Rodriguez, MD, Department of Pulmonary Medicine and Critical Care, John H. Stroger Hospital of Cook County, Chicago, IL, USA

Katayoun Rezai, MD, Department of Infectious Diseases, John H. Stroger Hospital of Cook County, Chicago, IL, USA; and Rush University, Chicago, IL, USA
}

Results: Of the 141 patients, 86 required mechanical ventilation, 50 received steroids, and 71 died. Regarding demographics, patients had a median age of 58 (interquartile range $[\mathrm{IQR}] 48,65)$, Hispanic $(57.4 \%, \mathrm{n}=81)$, and non-Hispanic Black $(37.5 \%, \mathrm{n}=53)$. The most prevalent comorbidities were hypertension $(49.6 \%, \mathrm{n}=70)$ and diabetes $(48.2 \%, n=68)$. Lower blood glucose levels on admission (125.5 vs. $148 \mathrm{mg} / \mathrm{dL}, \mathrm{p}=0.025$ ) and lower peak blood glucose levels on corticosteroids (215.5 vs. $361 \mathrm{mg} /$ $\mathrm{dL}, \mathrm{p}=0.0021)$ were associated with lower prevalence of mortality. Patients who were successfully extubated had a lower admission blood glucose (126.5 vs. $149 \mathrm{mg} / \mathrm{dL}$, $\mathrm{p}=0.0074$ ) and lower peak blood glucose on corticosteroids (217 vs. $361 \mathrm{mg} / \mathrm{dL}, \mathrm{p}=0.0023$ ).

Conclusions: Lower blood glucose on admission and lower maximum blood glucose on corticosteroids were associated with lower odds of mortality and successful extubation, regardless of preexisting diabetes. Hyperglycemia may be negating any potential benefit of corticosteroid therapy. These findings suggest that glucose control could be a parameter that impacts the outcome of patients receiving corticosteroids for COVID-19 pneumonia.

Keywords: corticosteroids; COVID-19; glycemic control; hyperglycemia.

COVID-19 continues to challenge the medical community worldwide, particularly in the intensive care unit. One main pathophysiologic effect of COVID-19 is an exaggerated inflammatory state in the host. For this reason, corticosteroids were promptly studied and have become the standard of care in treating severe COVID-19.

The strongest evidence comes from the RECOVERY (Randomised Evaluation of COVID-19 Therapy) collaborative group, an open-label trial in the United Kingdom that included 2,104 patients [1]. Patients were given either intravenous or oral dexamethasone, $6 \mathrm{mg}$ daily, for 10 days compared to standard care. This study concluded that dexamethasone administration in patients requiring 
oxygen or mechanical ventilation resulted in a lower 28-day mortality [1].

On the contrary, the METCOVID (Methylprednisolone as Adjunctive Therapy for Patients Hospitalized with COVID-19) study, a double-blinded placebo-controlled randomized clinical trial of 393 patients, evaluated outcomes in patients receiving methylprednisolone for COVID-19 and revealed no difference in 28-day mortality [2]. However, a subgroup analysis revealed that patients above 60 years of age did have a decrease in mortality. The treatment group also had more need for insulin during their hospital stay.

Despite their benefits, corticosteroids are known to have several adverse effects, one of which is hyperglycemia, which carries complications that might impact the hospital course of these patients. The RECOVERY Trial did not report adverse effects of corticosteroid use such as hyperglycemia.

The main objective of our study was to analyze the association between corticosteroids and COVID-19-related outcomes among patients admitted to the medical ICU (MICU) during the initial wave of the COVID-19 pandemic in the United States. We studied clinical factors related to mortality and successful extubation. We also describe glucose control related to steroids.

\section{Methods}

An observational study was conducted on 141 patients with a positive SARS-CoV-2 polymerase chain reaction (PCR) admitted to the MICU at a public safety net hospital in Chicago, Illinois between March 18 and June 7, 2020 (before corticosteroids were the standard of care for severe COVID-19). Inclusion criteria included: (1) 18 years of age or older; and (2) admitted to the MICU for COVID-19 pneumonia via documentation on the admission note by the critical care attending physician. Hospital employees admitted to the MICU during this period were excluded. Data on 150 patients were initially obtained, and nine patients were excluded for not meeting the inclusion criteria. Data extraction, via Cerner electronic medical records, was completed with a password-encrypted Microsoft Excel sheet. Data collectors were trained prior to commencement, and their performance was monitored. The data collectors met periodically to assure that all data collection was uniform and consistent. Any questions or discrepancies during collection were collected. One of the data collectors audited all data collection to assure uniformity and consistency between collectors.

Independent variables on demographics, laboratory, imaging studies, and clinical course were obtained through manual extraction of data from the electronic medical record (EMR) after Institutional Review Board (IRB) approval (number 20-104) from Audrean LaGrone, John H. Stroger Hospital of Cook County. Informed consent was waived and approved during the IRB approval process. Participants self-identified their ethnicity on admission if they were mentally capable to answer questions; if they unable to answer questions, staff completed the questionnaire for them. Patients answered from a predetermined set of traditionally narrow racial categories, one of which was "other" if unable to find the category that is the best fit. Corticosteroid data were manually extracted from the EMR, including the duration of treatment (measured in days), steroid initiation date, average dose, and maximum daily dose (in mg/day). Four corticosteroids were included in the analysis: methylprednisolone, dexamethasone, prednisone, and hydrocortisone. Glucose on admission was obtained on all patients, and peak glucose was obtained on patients who received corticosteroids $(n=50)$.

Bivariate analyses and logistic regression were performed to analyze the association between the independent variables (hospital days to start of steroids, hospital days to intubation, days of MICU stay, days intubated, glucose on admission, max glucose on steroids, BMI) with two outcomes: mortality and extubation. Characteristics of participants by mortality and extubation status were examined utilizing chi-square and Mantel-Haenszel chi-square tests for trend, as appropriate, to examine the relationship between mortality and extubation and categorical variables, whereas the nonparametric Wilcoxon signed-rank and Kruskal-Wallis tests were utilized to examine the relationship between mortality and extubation and continuous variables due to the distributions of all continuous variables examined being skewed to the right. Specifically, max glucose was skewed to the right (Shapiro-Wilk W, $\mathrm{p}=0.004$ ), glucose on admission was skewed to the right (Shapiro-Wilk W, $\mathrm{p}<0.0001$ ), hospital days to admission was skewed to the right (Shapiro-Wilk $\mathrm{W}, \mathrm{p}=0.0001$ ), total days of MICU stay was skewed to the right (Shapiro-Wilk W, p $<0.0001$ ), total days intubated was skewed to the right (Shapiro-Wilk $\mathrm{W}, \mathrm{p}<0.0001$ ), hospital days to start of steroid was skewed to the right (Shapiro-Wilk $\mathrm{W}, \mathrm{p}=0.0005)$, and hospital days to intubation was skewed to the right (Shapiro-Wilk W, $\mathrm{p}=0.0001$ ).

Independent variables with large magnitudes of association in unadjusted models were considered as variables of interest in separate adjusted models among the patients who received corticosteroids $(n=50)$ to estimate the total effect of each independent variable of interest on mortality. Potential confounding variables were selected for inclusion in adjusted models based on a priori knowledge about their interrelationships with the independent variables of interest and on mortality. All regression analyses were conducted utilizing Stata version 15.

\section{Results}

A total of 141 patients were admitted to the MICU from March 18 to June 7, 2020 with severe COVID-19 pneumonia and were included in the study. Fifty of these patients were admitted directly through the emergency department, and 91 were admitted from general medical floors. Of the 141 patients, 86 required mechanical ventilation, 50 received steroids, and 71 died. APACHE scores were calculated and showed no difference between patients receiving corticosteroids and those not receiving corticosteroids.

The patients were predominately older (median age, 58 years; interquartile range [IQR], 48, 65), Hispanic (57.4\%, $\mathrm{n}=81)$, and non-Hispanic Black (37.5\%, $\mathrm{n}=53$ ) (Table 1). The most prevalent comorbidities were hypertension $(49.6 \%$, $\mathrm{n}=70)$ and diabetes $(48.2 \%, \mathrm{n}=68)$.

The main factors for successful extubation during MICU stay, apart from natural logical associations (longer days of intubation and MICU stay) were: average glucose 
Table 1: Demographics and population comorbidities $(n=141)$.

\begin{tabular}{lr}
\hline & $\begin{array}{r}\text { n (\% of total } \\
\text { population) }\end{array}$ \\
\hline Median age, years (IQR) & $58(48,65)$ \\
Median body mass index, $\mathrm{kg} / \mathrm{m}^{2}(\mathrm{IQR})$ & $32(27,38)$ \\
Gender & \\
Male & $98(69.5 \%)$ \\
Female & $43(30.5 \%)$ \\
Race/ethnicity & \\
Non-Hispanic Black & $53(37.5 \%)$ \\
Non-Hispanic White & $6(4.3 \%)$ \\
Hispanic & $81(57.4 \%)$ \\
Asian & $1(0.0 \%)$ \\
Population comorbidities & \\
Hypertension & $70(49.6 \%)$ \\
Diabetes mellitus & $68(48.2 \%)$ \\
Chronic kidney disease & $20(14.2 \%)$ \\
Asthma & $17(12.1 \%)$ \\
Obstructive sleep apnea & $15(10.6 \%)$ \\
Chronic obstructive respiratory disease & $12(8.5 \%)$ \\
Heart failure (reduced or preserved ejection & $12(8.5 \%)$ \\
fracture) & \\
Coronary artery disease & $9(6.4 \%)$ \\
Cirrhosis & $7(4.9 \%)$ \\
End-stage renal disease & $6(4.3 \%)$ \\
Cancer & $5(3.5 \%)$ \\
\hline
\end{tabular}

${ }^{a}$ Race/ethnicity was obtained on admission and based on how patients self-identified. IQR, interquartile range.

on admission $126.5 \mathrm{mg} / \mathrm{dL}$ (IQR 108, 148) vs. $149 \mathrm{mg} / \mathrm{dL}$ (IQR 126, 254) $(\mathrm{p}=0.0074)$ and maximum glucose level with steroid administration $217 \mathrm{mg} / \mathrm{dL}$ (IQR 201, 282) vs. 361 (IQR $249,455) \mathrm{mg} / \mathrm{dL}(\mathrm{p}=0.0023$ ) (Table 2). Similar results were obtained in the mortality bivariate analysis, in which higher blood glucose levels on admission $125.5 \mathrm{mg} / \mathrm{dL}$ (IQR $108,159)$ vs. 148 (IQR 117, 249) ( $\mathrm{p}=0.025)$ and higher maximum blood glucose level with steroid administration $215.5 \mathrm{mg} / \mathrm{dL}$ (IQR 199, 277) vs. $361 \mathrm{mg} / \mathrm{dL}$ (IQR 248, 252.5) $(\mathrm{p}=0.0021)$ were associated with a higher prevalence of mortality. Obesity did not have significant association with extubation $\left(x^{2}=3.05 ; p=0.22\right)$ or mortality $\left(x^{2}=1.75 ; p=0.42\right)$.

A logistic regression was conducted to assess the association between the maximal glucose level among patients who were administered corticosteroids and mortality $(n=50)$ (Table 3). Increased odds of mortality were observed with higher levels of glycemia. For every rise in blood glucose level of $1 \mathrm{mg} / \mathrm{DL}$, the odds of death increased by $1.01(95 \% \mathrm{CI} 1.003,1.018)$. This association was adjusted for preexisting diabetes, which was not significantly associated with odds of mortality in our patient population.

In this subgroup analysis, we assessed the average max and delta change of glycemia in patients receiving
Table 2: Bivariate analyses of clinical characteristics and extubation and mortality.

\begin{tabular}{|c|c|c|c|}
\hline \multicolumn{4}{|c|}{ Intubations, $n=86$} \\
\hline & $\begin{array}{r}\text { Not extu- } \\
\text { bated } \\
n=60 \\
n, \%\end{array}$ & $\begin{array}{r}\begin{array}{r}\text { Extubated } \\
n=26\end{array} \\
n, \%\end{array}$ & p-Value \\
\hline Mortality due to COVID-19 & & & $<0.001$ \\
\hline No & $2(3.3)$ & $24(92.3)$ & \\
\hline Yes & $58(96.6)$ & $2(7.7)$ & \\
\hline Steroids & & & 0.16 \\
\hline No & $33(55.0)$ & $10(38.5)$ & \\
\hline$Y_{e s}^{a}$ & $27(45.0)$ & $16(61.5)$ & \\
\hline $\begin{array}{l}\text { Hospital days to start of ste- } \\
\text { roid (median, IQR) }\end{array}$ & $6(3,11)$ & $5.5(1,9.5)$ & 0.61 \\
\hline $\begin{array}{l}\text { Hospital days to intubation } \\
\text { (median, IQR) }\end{array}$ & $4(2,7)$ & $4.5(0,7)$ & 0.55 \\
\hline $\begin{array}{l}\text { Days of MICU stay (median, } \\
\text { IQR) }\end{array}$ & $9(5,15.5)$ & $17(13,26)$ & 0.0001 \\
\hline Days intubated (median, IQR) & $6(3,13)$ & $10.5(9,16)$ & 0.00011 \\
\hline $\begin{array}{l}\text { Glucose on admission (me- } \\
\text { dian, IQR) }\end{array}$ & $\begin{array}{r}149(126, \\
254)\end{array}$ & $\begin{array}{r}126.5(108, \\
148)\end{array}$ & 0.0074 \\
\hline $\begin{array}{l}\text { Max glucose on steroids (me- } \\
\text { dian, } I Q R)^{b}\end{array}$ & $\begin{array}{r}361(249 \\
455)\end{array}$ & $\begin{array}{r}217(201, \\
282)\end{array}$ & 0.0023 \\
\hline $\mathrm{BMI}, \mathrm{kg} / \mathrm{m}^{2}$ & & & 0.22 \\
\hline Normal & $4(6.6)$ & $5(19.2)$ & \\
\hline Overweight & $19(31.7)$ & 7 (26.9) & \\
\hline Obese & $37(61.7)$ & $14(53.8)$ & \\
\hline
\end{tabular}

\begin{tabular}{|c|c|c|c|}
\hline \multicolumn{4}{|c|}{ Mortality, n=141 } \\
\hline Mortality due to COVID & $\begin{array}{r}\text { Alive } \\
n=70 \\
n, \%\end{array}$ & $\begin{array}{r}\text { Deceased } \\
n=71 \\
n, \%\end{array}$ & p-Value \\
\hline $\begin{array}{l}\text { Hospital days to intubation } \\
\text { (median, IQR) }^{\mathrm{a}}\end{array}$ & $5(1,7)$ & $4(2,7)$ & 0.68 \\
\hline $\begin{array}{l}\text { Days of MICU stay (median, } \\
\text { IQR) }\end{array}$ & $8(4,17)$ & $8(5,14)$ & 0.88 \\
\hline Days intubated (median, IQR) & $10(9,16)$ & $7(3,13)$ & 0.0019 \\
\hline $\begin{array}{l}\text { Glucose on admission (me- } \\
\text { dian, IQR) }\end{array}$ & $\begin{array}{r}125.5(108, \\
159)\end{array}$ & $\begin{array}{r}148(117, \\
249)\end{array}$ & 0.025 \\
\hline $\begin{array}{l}\text { Max glucose on steroids (me- } \\
\text { dian, IQR) }\end{array}$ & $\begin{array}{r}215.5(199, \\
277)\end{array}$ & $\begin{array}{r}361(248, \\
252.5)\end{array}$ & 0.0021 \\
\hline $\begin{array}{l}\text { Hospital days to start of ste- } \\
\text { roid (median, IQR) }\end{array}$ & $4.5(1,11)$ & $5(1.5,9)$ & 0.72 \\
\hline $\mathrm{BMI}, \mathrm{kg} / \mathrm{m}^{2}$ & & & 0.42 \\
\hline Normal & $9(12.8)$ & $5(7.0)$ & \\
\hline Overweight & $18(25.7)$ & $23(32.4)$ & \\
\hline Obese & $43(61.4)$ & $43(60.5)$ & \\
\hline
\end{tabular}

*Wilcoxon signed-rank and Kruskal-Wallis tests were utilized to examine the relationship between mortality and extubation and continuous variables. Chi-squared tests were used to examine the relationship between mortality and extubation and categorical variables. ${ }^{a} n=7$ patients were on steroids but not intubated. ${ }^{b} n=50$ patients on steroids. BMI, body mass index; IQR, interquartile range; MICU, medical ICU. 
Table 3: Logistic regression: effect of max glucose on steroids and mortality due to COVID-19, controlling for diabetes mellitus, $n=50$.

\begin{tabular}{lrrr}
\hline & Odds ratio & $95 \% \mathrm{Cl}$ & p-Value \\
\hline Max glucose on steroids & 1.01 & $1.003,1.018$ & 0.006 \\
Diabetes mellitus & 0.711 & $0.169,2.988$ & 0.642 \\
\hline
\end{tabular}

$\mathrm{Cl}$, confidence interval.

corticosteroids (Table 4). Patients who received corticosteroids and died had a greater peak as well as delta change in glucose level from admission. The delta change was $145 \mathrm{mg} / \mathrm{dL}$ with a max average $337 \mathrm{mg} / \mathrm{dL}$ compared to those who survived while receiving corticosteroids with a max average of $235 \mathrm{mg} / \mathrm{dL}$ with a delta change of $85 \mathrm{mg} / \mathrm{dL}$.

\section{Discussion}

Early in the pandemic, Zhu et al. [3] reported that wellcontrolled blood glucose levels were associated with decreased mortality in patients with type 2 diabetes and COVID-19 in 7,337 patients (Hazard ratio=0.14, 95\% CI, 0.03-0.06, p=0.008). Fadini et al. [4] reported that hyperglycemia on admission was associated with COVID-19 severity in 413 patients, whereas Liu et al. [5] found that hyperglycemia and a history of diabetes mellitus on admission predicted worse outcomes for COVID-19 in 214 patients. Liu et al. [5] also reported that blood glucose on admission was an independent risk factor for critical illness in COVID-19. This link between glucose metabolism and COVID-19 may be explained by our knowledge of other coronaviruses, such as Middle East Respiratory Syndrome (MERS) and severe acute respiratory syndrome (SARS). It has been postulated that these viruses have tropism to the pancreatic islet cells, causing damage and impairing their function [6]. This would lead to impaired metabolism and glucose regulation. Our study is one of the first to analyze the relationship between maximum glucose on steroids and COVID-19 outcomes.

We found that higher blood glucose on admission and higher maximum glucose on corticosteroids were associated with higher odds of mortality. This association was present after controlling for underlying diabetes mellitus. A subanalysis showed that among the patients who received corticosteroids $(n=50)$, the patients that died had a greater change in glucose when started on steroids $(+145 \mathrm{mg} / \mathrm{dL}$, $\mathrm{n}=28, \mathrm{p}=<0.001)$ compared to the patients who survived $(+85 \mathrm{mg} / \mathrm{dL}, \mathrm{n}=22, \mathrm{p}=<0.001)$. There was no significant difference in the glucose level on admission between patients who received corticosteroids and those who did not, indicating that patients who received corticosteroids did not have a predisposition for higher glucose on admission.
Table 4: Change in glucose between admission and maximum in the corticosteroid arm.

\begin{tabular}{|c|c|c|c|}
\hline $\begin{array}{l}\text { Mean (SD) glucose } \\
\text { on admission }\end{array}$ & $\begin{array}{l}\text { Mean (SD) max } \\
\text { glucose }\end{array}$ & $\begin{array}{l}\text { Mean (SD) change } \\
\text { in glucose }\end{array}$ & $p$-Value \\
\hline 192 mg/dL (95) & $\begin{array}{l}337 \mathrm{mg} / \mathrm{dL} \\
(121)\end{array}$ & +145 mg/dL (109) & $<0.0001$ \\
\hline
\end{tabular}

Change in glucose between admission and maximum among patients who did not die due to COVID-19, who were on steroids $(n=22)$

\begin{tabular}{llll}
\hline $\begin{array}{l}\text { Mean (SD) glucose } \\
\text { on admission }\end{array}$ & $\begin{array}{l}\text { Mean (SD) max } \\
\text { glucose }\end{array}$ & $\begin{array}{l}\text { Mean (SD) change } \\
\text { in glucose }\end{array}$ & -Value \\
$150 \mathrm{mg} / \mathrm{dL}(63)$ & $235 \mathrm{mg} / \mathrm{dL}(76)$ & $+85 \mathrm{mg} / \mathrm{dL}(85)$ & 0.0001 \\
\hline
\end{tabular}

SD, standard deviation.

Factors associated with successful extubation in COVID-19 patients have not been widely described in the literature. We observed that patients who were successfully extubated had a lower glucose on admission and a lower maximum glucose on corticosteroid treatment when compared to those unable to be extubated. While the pathophysiology behind this outcome is unclear, Callahan and Supinski [7] proposed that hyperglycemia can induce diaphragmatic weakness through oxidative stress, leading to longer intubation time. This is a plausible explanation of this outcome, as well as a point of further research.

There is literature on admission glucose being associated with worsened outcomes and mortality in COVID-19 patients $[3,4,8-10]$. The peak glucose level of patients receiving corticosteroids having an impact on mortality is a novel finding. Hyperglycemia is a known effect of corticosteroid use, and any potential benefit of corticosteroid therapy in the setting of COVID-19 may be overshadowed by the negative impact of uncontrolled hyperglycemia. These findings provide further evidence that patients with elevated glucose level on admission have higher odds of mortality. These novel findings also indicate that adequate glucose control in patients who have received corticosteroids for severe COVID-19 pneumonia may improve their chance of successful extubation and survival.

The groups were studied after identification and adjustment of potential confounding variables to increase internal validity. Due to the nature of the study, random sampling from an existing pool of patients was not conducted. Although our results are promising, the sample size was relatively small (141 patients in total, 50 of which received steroids because it was not yet standard of care), and the study design was cross-sectional, limiting our ability to infer causality. Based on this study, we cannot comment on the 
proper range of blood glucose control that should be attained, specifically in patients with COVID-19. Future research should examine this topic. It is difficult to ascertain whether the results could be applied to a more general population of COVID-19 patients, because the sample size is small. A larger sample would allow for stronger associations.

\section{Conclusions}

Lower blood glucose on admission and lower maximum blood glucose on corticosteroids were associated with lower odds of mortality and successful extubation, regardless of whether there was preexisting diabetes. Hyperglycemia may be negating any potential benefit of corticosteroid therapy. Although there may not be an established range of glucose control in patients receiving corticosteroids for COVID-19 pneumonia, it appears that this factor plays an important role in patient outcomes.

Research funding: None reported.

Author contributions: All authors provided substantial contributions to conception and design, acquisition of data, or analysis and interpretation of data; all authors drafted the article or revised it critically for important intellectual content; all authors gave final approval of the version of the article to be published; and all authors agree to be accountable for all aspects of the work in ensuring that questions related to the accuracy or integrity of any part of the work are appropriately investigated and resolved.

Competing interests: None reported.

Ethical approval: This study was reviewed and approved by the John H. Stroger Institutional Review Board.

\section{References}

1. Horby P, Lim WS, Emberson JR, Mafham M, Bell JL, Linsell L, et al. Dexamethasone in hospitalized patients with Covid-19 preliminary report. N Engl J Med 2021;384:693-704.

2. Jeronimo CMP, Farias MEL, Val FFA, Sampaio VS, Alexandre MAA, Melo GC, et al. Methylprednisolone as adjunctive therapy for patients hospitalized with COVID-19 (Metcovid): a randomised, double-blind, phase IIb, placebo-controlled trial. Clin Infect Dis 2021;72:e373-81.

3. Zhu L, She ZG, Cheng X, Qin JJ, Zhang XJ, Cai J, et al. Association of blood glucose control and outcomes in patients with COVID-19 and pre-existing type 2 diabetes. Cell Metab 2020;31: 1068-77.e3.

4. Fadini GP, Morieri ML, Boscari F, Fioretto P, Maran A, Busetto L, et al. Newly-diagnosed diabetes and admission hyperglycemia predict COVID-19 severity by aggravating respiratory deterioration. Diabetes Res Clin Pract 2020;168:108374.

5. Liu SP, Zhang Q, Wang W, Zhang M, Liu C, Xiao X, et al. Hyperglycemia is a strong predictor of poor prognosis in COVID-19. Diabetes Res Clin Pract 2020;167:108338.

6. Ilias I, Zabuliene L. Hyperglycemia and the novel Covid-19 infection: possible pathophysiologic mechanisms. Med Hypotheses 2020;139:109699.

7. Callahan LA, Supinski GS. Hyperglycemia-induced diaphragm weakness is mediated by oxidative stress. Crit Care 2014;18:R88.

8. Liu Q, Chen H, Li J, Huang X, Lai L, Li S, et al. Fasting blood glucose predicts the occurrence of critical illness in COVID-19 patients: $a$ multicenter retrospective cohort study. J Infect 2020;81:e20-3.

9. Wang S, Ma P, Zhang S, Song S, Wang Z, Ma Y, et al. Fasting blood glucose at admission is an independent predictor for 28-day mortality in patients with COVID-19 without previous diagnosis of diabetes: a multi-centre retrospective study. Diabetologia 2020; 63:2102-11.

10. Zhang B, Liu S, Zhang L, Dong Y, Zhang S. Admission fasting blood glucose predicts 30-day poor outcome in patients hospitalized for COVID-19 pneumonia. Diabetes Obes Metab 2020;22:1955-7. 